\title{
Computer-supported problem posing by annotated expressions: content-first design and evaluation
}

\author{
Hercy N. H. Cheng • Yu-Lin Weng • Tak-Wai Chan
}

Received: 14 September 2014/Revised: 20 October 2014/Accepted: 24 October 2014/

Published online: 1 November 2014

(C) Beijing Normal University 2014

\begin{abstract}
Because previous research has indicated a highly positive relationship between problem solving and posing, the process of problem solving can be adopted to design materials for problem posing. In this vein, the purpose of this study is to design a learning system for problem posing by annotated expressions through adoption-based research, in particular, a content-first design approach. More specifically, this study, inspired by solution trees, first designs annotated expressions for problem posing as content samples. In order to assess the effect on the assessment goal of problem-solving abilities, this study conducts an experiment, whose results show that problem posing by annotated expression may improve students' performance on problem translation and two-step problem formulation abilities more than problem posing by pure expressions. Accordingly, this study then designs a computer-based learning activity to support and sustain such a method for problem posing. Finally, a classroom adoption, conducted in an authentic classroom, may suggest a positive outcome and future research on designing computer-based problem posing.
\end{abstract}

Keywords Problem posing $\cdot$ Annotated expressions $\cdot$ Solution trees $\cdot$ Content-first design

H. N. H. Cheng · Y.-L. Weng · T.-W. Chan

Graduate Institute of Network Learning Technology, National Central University, Jhongli, Taiwan

H. N. H. Cheng $(\bowtie)$

Collaborative \& Innovative Center for Educational Technology, Central China Normal University,

Wuhan, China

e-mail: hercycheng.tw@gmail.com

Y.-L. Weng

Department of Information Management, St. Mary's Junior College of Medicine, Nursing and Management, Yilan, Taiwan 


\section{Introduction}

While mathematics curriculum still focuses on problem solving, problem posing has also been emphasized with the reform of mathematics education in various countries. In United States, for example, National Council of Teachers of Mathematics (1989) explicitly stated that students should recognize and formulate their own problems in an early document. Later they specifically suggested that students should formulate problems from given situations and create new problems by modifying the conditions of a given problem (NCTM 1991, 1995). In other words, students were not supposed to solve problems only. Instead, students may also change data, adjust variables and construct a new problem (NCTM 2000).

Compared with the education in western countries, Chinese curriculum was usually criticized for stressing too much in basic skills and knowledge (Zhang 2006). For this reason, the Ministry of Education of Taiwan (2000) emphasized the aim of developing students' ability to formulate and solve problems in a nine-year integrated curriculum for mathematics. Similarly, China carried out a mathematics curriculum reform movement (Cai \& Nei 2007). In particular, China included problem posing in mathematics curriculum. Furthermore, the standards for the compulsory education required students to pose problems, understand problems, and apply knowledge learnt to solve authentic problems (Basic Education Curriculum Material Development Center 2001). In summary, various countries had started to incorporate problem posing into mathematics curricula based on problem solving.

In these mathematics curricula, problem posing was regarded as an extension of problem solving, specifically, a creation process after problem solving (Dillon 1982). In a sense, problem solving was a form of consuming mathematical knowledge, while problem posing was a form of creating mathematical knowledge, which involved imitation, conversion, and integration of mathematical knowledge. In other words, while students applied mathematical knowledge in problem solving, they may create mathematical knowledge in problem posing. Research also showed that problem posing could enhance students' problem-solving abilities (Brown \& Walter 1993; English 1996). As a matter of fact, problem posing could also be regarded as a source of problem solving. Leung (1993) modified Pólya's framework of problem solving (Pólya 1945) to four steps of problem posing-posing a problem, devising a solution plan, carrying out the plan, and looking back the solution. More specifically, when students played the role of problem posers, they had already understood the problem that they posed. Because they could easily realize the content and structure of the problem, they were able to solve it and looking back the solution. These studies suggested that problem solving and posing were mutually complementary mathematics learning activities.

Besides, research also showed that problem posing may facilitate creative thinking (Pelczer, \& Rodriguez 2010; Silver 1997; Yuan \& Sriraman 2011). In terms of a revised Bloom's taxonomy of educational objectives (Anderson \& Krathwohl 2001), problem solving included remembering, understanding, applying, analyzing, and evaluating without creating. On the contrary, problem posing may unlock the limitation of rote and comprehension, encouraging students to apply what they had learnt from a whole new perspective, to analyze all possibilities, and 
to evaluate reasonable contexts, and finally to create an elaborate work. In other words, when creation became an educational objective, students were able to synthesize the abilities mentioned above and then creating new knowledge.

In addition, problem posing actually facilitated not only students' cognition but also their positive disposition (NCTM 2000). Research indicated that problem posing potentially lessen mathematical anxiety because students may feel less pressure (Brown \& Walter 2005). Problem posing may also provide students with a sense of ownership for contributing their own knowledge, resulting in a high level of engagement and interests (Lavy \& Shriki 2007). As a result, problem posers could be active learners, who were willing to invest their efforts to develop their own thinking (Freire 2001). In a classroom with problem posing, students were not listeners any more. Instead, they communicated with each other and their teachers through creation.

However, Silver \& Cai (1996) found that although students with high problemsolving abilities could construct more difficult and complicated problems, those students with low problem-solving abilities tended to pose easy and simple problems. The findings suggested that low-ability students still need additional assistance for designing more meaningful problems. For this reason, the purpose of this study aims at designing a computer-based learning material to facilitate students to construct advanced mathematical word problems. Besides, this study also attempts to develop a sustainable system for problem posing in authentic classrooms, where technology-enhanced learning involved many complicated aspects, such as content, activities, students, and teachers.

Therefore, as suggested by Chang et al. (2009), this paper adopted a content-first design approach instead of technology first. More specifically, a content-first design approach included content samples, an assessment goal, a learning flow, and adoption. In this vein, the paper first described mathematical problem posing theories in which the content was grounded ("Mathematical Problem Solving" section), then the design of content samples ("Design of Mathematical Problem Posing Materials" section), a paper-based experiment for assessing the learning goal ("Paper-based Experiment" section), the design of a computer-supported problem posing system ("Computer Supported Problem Posing by Annotated Expressions" section), and its classroom adoption ("Classroom Adoption" section).

\section{Mathematical Problem Solving}

\section{Definition}

Mathematical problem posing is a personalized process in which students construct meaningful mathematical questions based on their mathematical experience (Stoyanova \& Ellerton 1996). In other words, problem posers may connect their previous mathematical knowledge and experience with new scenarios, numbers, or figures. Such a process of organizing a mathematical problem is problem posing.

Duncker (1945) defined two different concepts of problem posing: constructing a new problem from a mathematical context, or reformulating a given problem. The 
definition was consistent with the objectives of American National Council of Teachers of Mathematics $(1991,1995)$ as well as Ministry of Education of Taiwan (2000), as mentioned earlier. Such a definition was widely adopted in recent research (see also Cai \& Hwang 2002; Kar et al. 2010). Silver (1994) further indicated that problem posing could be conducted before, during or after problem solving. More specifically, before solving a problem, students may generate a problem in a given context; when solving a problem, students may generate a similar problem by modifying its target or conditions; alternatively, after having an experience of solving a problem, students may generate a related new problem.

For looking into problem posing, Stoyanova \& Ellerton (1996) proposed a research framework, in which problem posing incorporated the forms of free, semistructured, and structured situations. Free situations invited students to pose a problem in an artificial or natural context, for example, problem posing by a billiard task (Koichu \& Kontorovich 2013). Semi-structured situations allowed students to complete the structure of a problem by applying their own knowledge, skills, and experience in an open context, for example, problem posing by arithmetic operations (Arikan \& Unal 2014). Structured situations required students to pose a problem given a specific problem, for example, problem posing by changing conditions (Brown \& Walter 1993). Among these forms, semi-structured situations could moderately assist students to pose a problem. Therefore, this study aims at designing a semi-structured material for problem posing, so that students may create mathematical problems with the supports of representations.

The process of problem solving and posing

Previous research indicated that problem posing was not independent from problem solving (Silver 1994; Silver \& Cai 1996; Cai \& Hwang 2002; English 2003). For this reason, before investigating the process for problem posing, researchers should understand the process for problem solving. Pólya (1945) had provided a general framework consisted of four phases: understanding the problem, devising a plan, carrying out the plan, and finally, looking back the solution. In particular, he pointed out that students had to find out the connections among the data as well as between the unknown and the data in the second phase. Such connections suggested that the structure of a problem might potentially provide a solution.

From a psychological perspective, Mayer $(1985,1992)$ suggested a similar but detailed framework for solving word problems: problem translation, problem integration, solution planning, and solution execution. The first two stages were also termed as problem representation. Compared with Pólya's framework, problem representation could be regarded as an approach to understanding a problem. Furthermore, the stage of problem translation was to transform the problem text into several pieces of useful information, which involved linguistic and semantic knowledge. In other words, students had to use their background knowledge to interpret the meaning of the story in a word problem. On the other hand, problem integration was to re-structure these pieces of information as a representation of the problem for plan and execution later. The stage of problem integration involved schematic knowledge, which was the ability to identify the problem type and 
categorize it into an archetype of familiar problems. As for the last two stages, solution planning, and solution execution were also called problem solution. Furthermore, the stage of solution planning required strategic knowledge to devise an appropriate strategy for solving the problem, while the stage of solution execution required procedural knowledge to perform the strategy correctly.

Based on aforementioned frameworks, this paper proposes a more detailed framework for mathematical problem solving in terms of intermediate products (See the upper part of Fig. 1). First, because mathematics is used to solve real problems in our real life, the word problems in a textbook are usually a simplified form of the problem situation using natural language. Then, when a student reads a word problem, he/she has to realize how to abstract the target and related conditions in the word problem, translating it from natural language into several pieces of solvable information. The student also has to integrate these pieces of information with the supports of problem structures or mathematical representations (e.g., line-segment diagrams) in order to restructure the problem and plan how to solve the problem. For a novice problem solver, the structures and representations should be externalized for solving a more complex mathematical problem. Finally, through expressions and calculation, the student gets the answer of the problem situations, which should be checked by looking back in the original problem context.

Problem posing can be regarded as a reverse process of problem solving (see the lower part of Fig. 1). First, like the process of problem solving, given a problem situation, students may define a word problem in a written format. Second, given a problem target with several conditions, students may attempt to organize them into a reasonable word problem. Third, when students are provided with the structure or representation of a problem, they may learn how to convert it into a word problem by figuring out its meaning. Fourth, as for arithmetic expressions, students may contextualize the equations in order to generate a word problem. Fifth, as for answers, students may tell a story for creating a word problem. By following the framework, the next section will enumerate several studies on computer-based mathematical problem posing.

\section{Computers-based mathematical problem posing}

During the last decade, researchers were dedicated to designing various systems for problem posing. More specifically, they contributed to incorporating peer assessment into the procedure of problem posing by taking advantage of network technology, such as QPPA (Yu 2011), QSIA (Barak \& Rafaeli 2004), and QPIS (Lan \& Lin 2011). However, many of them focused on domain-independent problem types. Furthermore, most studies required students to generate multiplechoice questions, while some studies included matching questions and even openended questions.

On the other hand, the research on computer-based mathematical problem posing could be divided into two categories. The first category was developed on the basis of Leung's framework (1993), emphasizing the process of problem solving after problem posing. For examples, Chang et al. (2012) developed a game-based learning system, Millionaire, to engage students in individual problem posing. In 


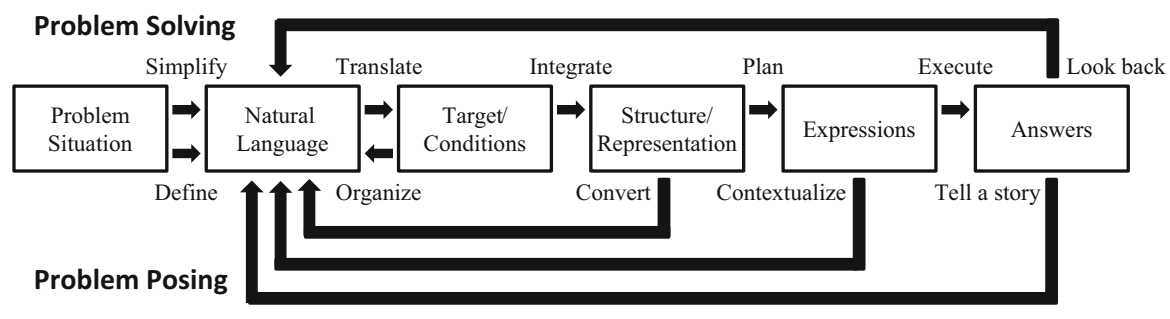

Fig. 1 Framework for mathematical problem solving and posing

addition, Lin (2010) developed a CPPS system to facilitate students to pose and solve problems collaboratively. The second category, on the other hand, focused on providing students with various materials in the process of problem posing. Research in this category could be described as follows according to the aforementioned framework of intermediate products in the problem solving/posing process.

The first type of intermediate products is problem situation, including picture, story, and authentic problems in our real life. This type can be regarded as a free form of problem posing (Stovanova \& Ellerton 1996). These materials for problem posing provide students a direction for creation, facilitating them to imagine various word problems. For example, Birch \& Beal (2008) designed an AnimalWatch tutoring system to allow students to devise mathematical problems related to endangered animals. By providing a list of endangered animals and their pictures, the system may engage students in generating interesting problems by applying their mathematical knowledge.

The second type is natural language, including example of word problem and learnt lesson. Teachers may use a structured word problem as an example for problem posing, so that students may imitate it to pose their own problem. Teachers may also use their textbooks, so that students can imitate the word problems in the textbooks after they learn a lesson. Pólya (1945) specifically proposed a method which allowed students to revise the known and unknown numbers in a given word problem for creating a new one. Similarly, Kojima \& Miwa (2008) designed a support system to facilitate diverse thinking in mathematical problem posing by allowing students to change a given example. More specifically, students may modify the situations and variables in the solutions to create various word problems (Kojima et al. 2009).

The third is to provide students with solvable conditions and a problem target, so that they can re-organize the problem. By providing several problem conditions, for example, a MONSAKUN system was designed so that students had to determine appropriate conditions and their logical order to construct a word problem (Hirashima et al 2006, 2008; Yamamoto et al. 2013). The process may help student understand the components of a word problem and the relationship between conditions. However, because conditions are close to a word problem, such a material is easier and suitable for low-graded or low-ability students to pose a word 
problem. In fact, research has showed that even first graders are able to pose correct word problems for one-step addition and subtraction (Yamamoto et al. 2012).

The fourth type is structures or representations, which may guide students to design a word problem with the supports of mathematical concepts and schemas. Because novice problem solvers are usually unfamiliar with problem structures, graphical representation, or mathematical vocabulary, this form of materials for problem posing is more difficult for them. However, practicing how to convert graphical representation or mathematical vocabulary into a word problem may help student learn how to solve a problem in the future.

The fifth type is expressions or problem-solving processes. Students can contextualize an expression to imagine the real meaning of the expression. Besides, expressions can also be adopted so that students may figure out the patterns of them. Finally, the sixth material is answers with or without units. Researchers and teachers may require students to tell a story of a word problem, which may involve the answers with certain units. Alternatively, the requirement can also include operands with or without units, which may engage students in the same activity of storytelling.

Although the last three types are educationally beneficial to students' problem posing, there are few studies on designing a computer-based version. Therefore, it is needed to design these types as well as to investigate their effects. For avoiding the complexity, this paper focuses on designing a structured representation to assist students to pose a mathematical word problem.

\section{Design of mathematical problem posing materials}

Previous research showed that problem solving and posing shared many common parts. The intermediate products in a problem solving process could be helpful to design materials for problem posing. In this study, the design of materials for problem posing was inspired by solution trees, which will be introduced in this section.

\section{Solution trees}

In order to assist students to pose word problems with a clear structure, this study adopts the concept of solution trees, proposed by Aebil et al. (1986; see also Derry \& Hawkes 1993). The concept is similar to a data structure in operation systems. More specifically, a solution tree is mainly consisted of two parts: label nodes and operation nodes. Each label node has a label and a value, for example, "the length of a scarf" and " $165 \mathrm{~cm}$," respectively; each operation node is the operation in an expression, for example, subtraction. Therefore, a basic solution tree has three label nodes and one operation node.

Following this idea, several studies used solution trees to design computerassisted problem-solving system (Derry \& Hawkes 1993; Reusser 1996). With solution trees, students may realize the complex structures of a mathematical word problem and then turn their solutions into a form of solution trees. Chang et al. 
(2006) further employed solution trees to diagnose students' difficulties in their process of problem solving, proving that solution trees could improve the performance of low-ability students on problem solving.

These studies suggested that solution trees may help student solve their word problem in terms of visualizing the structure of the problem. This method provides students with a map for problem understanding. When problem solvers use a solution tree to solve a problem, they may find the information extracted from the problem situated in the labels of the nodes. In other words, solution trees may help them notice the complex structure and realize the relationship and in turn have the potential for assisting problem posing.

Solution trees as problem posing materials

Based on the concept of solution trees, this study designs the scaffold of annotated arithmetic expressions for problem posing. As shown in Fig. 2a), more specifically, a one-step expression is annotated to provide prompts for problem posing. For instance, in an expression of " $8 \times 12=$ ?", the multiplicand " 8 " is annotated with a label node of the "number of people per group" while the multiplier " 12 " is annotated with the "number of groups". With the meaning of the label nodes, students may devise a reasonable word problem to fit the requirement of the given context.

It should be noted that a one-step expression is not represented in a structure of trees. Instead, it maintains its expression format, with which students may be more familiar than the structure of trees. In particular, for lower graders, a one-step expression is simple enough. A structure of trees may increase the cognitive load of students, hindering them from problem posing and learning. For this reason, this study adopts only label nodes and an operation node in a one-step expression.

For a two-step expression, which students may learn in the third grade, the annotated arithmetic expression uses a hierarchy to demonstrate an inner step. As illustrated in Fig. 2b, the inner step (i.e., the lower expression) should be solved earlier than the outer step (the higher expression), which is closer to the final answer. Both steps remain their formats of expressions, including the parentheses, which may indicate the calculation order. For instance, the multiplicand in the previous example can be extended to the sum of people in two parts, shown in Fig. 2b. Accordingly, students have to imagine a reasonable context that each group can be divided into two parts.

However, a previous study found that students lack diversity when problem posing with pure expressions (English 1998). Therefore, the annotation on the label nodes should guide students to devise various problems without limiting students' creative thinking. In the inner step of the previous example, for instance, the annotations are "a part of the number of people" and "another part of the number of people" instead of specific meanings, such as "the number of males" and "the number of females". Some students may imagine one part as higher graders and the other part as lower graders in a school, while some students may consider fast and slow runners in an athletic competition. In other words, the annotation of label nodes should be generalized enough so that students may pose problems with various scenarios. 


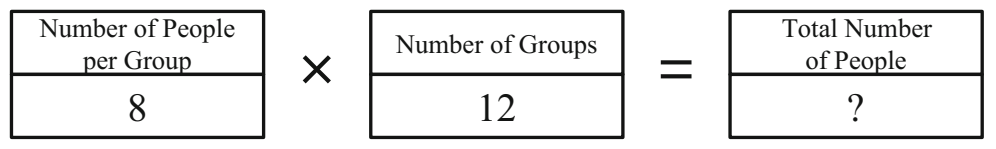

(a)

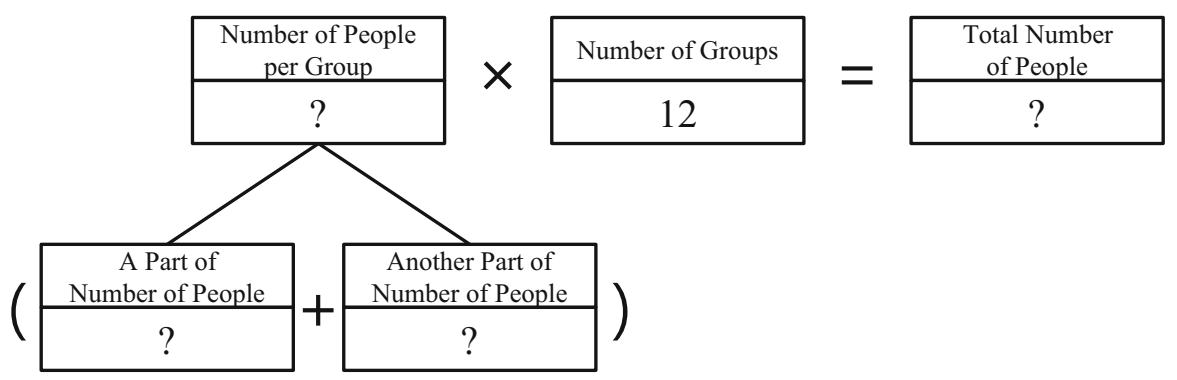

(b)

Fig. 2 Materials for problem posing by annotated expressions. a A one-step expression. b A two-step expression

\section{Paper-based experiment}

Before designing a computer-based system, this study carried out a paper-based experiment for evaluating the effect of annotated expressions on an assessment goal, which was the problem-solving abilities.

\section{Research questions}

Although problem posing can enhance the ability to solve problems in general, the effect of annotated expressions is still unclear. In this vein, the experiment aimed at further investigating the effect of problem posing by annotated expressions on problem-solving ability. For this purpose, this study took problem posing by pure expressions as the control group. On the other hand, this study adapted Mayer's framework (1992) for assessing problem-solving ability. As mentioned earlier, the framework comprised four stages of translation, integration, planning, and execution. Furthermore, while the first two stages could be regarded as the abilities to understand problems, the last two stages emphasized the abilities to formulate and calculate expressions. Therefore, this study intended to evaluate students' problem-solving ability as a whole and their performance in the first three stages. This study excluded the last stage of execution because it involved only calculation ability. More specifically, this experiment concerned the following research questions.

1. Did problem posing by annotated expressions or pure expressions better increase students' problem-solving abilities in general? 
2. Did problem posing by annotated expressions or pure expressions better increase students' performance in the stages of translation and integration?

3. Did problem posing by annotated expressions or pure expressions better increase students' performance in the stage of planning to solve one-step and two-step problems?

\section{Settings}

There were 29 fourth graders (including 15 boys and 14 girls with an average age of 9.5 years) participating in this study. They were all the students in the same class of an elementary school located in the countryside in Taoyuan county of Taiwan. Furthermore, because the school had normally distributed all students to classes in their third grade according to their previous achievement, the distribution of the selected class could be viewed similar to the other classes'. Before the experiment, all students participated a pre-test in problem-solving abilities, which will be described in the next section. According to the result of the pre-test, the students were sorted and then divided into an experimental group $(N=15)$ and a control group $(N=14)$ by ad lib matching, so that the averages of both groups were close to equivalence. An independent sample $t$ test showed that there was no significant difference between the problem-solving abilities of both groups $(t(27)=-0.065$, $p>.05)$.

This experiment took five sessions of classes within 3 weeks and each session took $40 \mathrm{~min}$. Both groups posed their own problems at the same time in the same classroom and received the same instructions. During the five sessions, both groups had to pose 16 one-step word problems and 8 two-step problems. More specifically, for one-step word problems, there were four problems in each category of additions, subtractions, multiplications, and divisions, while, for two-step word problem, there were two problems in each category of multiplication-then-addition, multiplicationthen-subtraction, addition-then-multiplication, and subtraction-then-multiplication.

The only difference between these two groups was the type of materials for problem posing. During the experiment, the experimental group was required to pose problems by annotated expressions. For example, the students in the experimental group were provided with annotated expressions like " 8 [the number of people per group] $\times 12$ [the number of groups] $=$ ? [total number of people]", as shown in Fig. 2. On the other hand, the control group had to pose problems by pure expressions. More specifically, the students in the control group were only given number sentences like " $8 \times 12=$ ?". In terms of the problem posing process (Fig. 1), the experimental group received the form of structure/representations, while the control group received the form of expressions.

During the experiment, six researchers took observation notes of students' behaviors. Although these notes did not directly response to the research questions, they may reveal students' emotions in addition to their cognition. Besides, these notes could be used to assist the design of a computer-based version in the next phrase. In addition to students, after every session, the authors would have an 
informal talk with the teacher, which may show the teacher's opinions and needs. In the end of the experiment, all students took a post-test in problem-solving abilities, as the pre-test. The results of the experiment may help the investigation of the difference in the effects between the forms of structure/representations and expressions.

Assessment of problem-solving abilities

This study adopted a self-made assessment of problem-solving abilities according to Mayer's framework for solving word problems (1992). More specifically, the assessment included translation, integration, and planning. Compare to Mayer's framework, the part of execution was absent from the assessment, because this study only focused on the ability to understand the problems and to plan the solutions without testing their calculation abilities.

In the assessment, there were 32 questions and every question scored one point if correct. In terms of translation, there were four multiple-choice questions, which required students to rephrase word problems in another way. For example, one of them was "Department store A had 10 levels. Department store B was higher than department store A by 7 levels. Therefore, (1) department store A was higher, (2) both department stores were equally high, (3) the difference between two buildings was 7 levels, and (4) department store B had 7 levels." In this question, students did not need to calculate the numbers. Instead, they had to understand the meaning of the statements.

In terms of integration, there were four multiple-choice questions, which aimed at testing whether students could distinguish the statements that helped problem solving from superfluous statements in word problems. For this purpose, every question of integration contained three statements, among which two statements were useful to answer the question. For example, one question was "Dad brought 2 boxes of chocolates and spent 540 dollars. Each box had 18 chocolates. How many chocolates did dad buy? (1) $540 \div 18$, (2) $540 \div 2$, (3) $180 \div 2=90$, and then $90 \times 540$, (4) $18 \times 2$." In this question, the superfluous statement was 540 dollars. If a student used 540 in his/her solution, he/she failed to integrate information in the question.

In terms of plan, students were required to solve four one-step problems and four two-step problems. Specifically, they were asked to formulate arithmetic expressions for each problem. As mentioned earlier, this category aimed at testing their ability to formulate expressions. For this reason, if they could make expressions correctly, they could score the points regardless of the correctness of calculation.

In order to response the first research question, which aimed at examining the difference between the effects of problem posing by annotated expressions and pure expressions on problem-solving abilities, a two-way analysis of variance (ANOVA) was conducted with groups (the experimental and control groups) as a betweensubject variable and time (the pre-test and post-test) as a within-subject variable. For responding the second research question, two paired sample $t$ tests were carried out on the improvement of both groups in each stage of problem translation and integration. For the third research questions, two paired sample $t$ tests were carried 
out on the improvement of both groups in the stage of planning for solving one-step and two-step word problems.

\section{Results}

The effect on general problem-solving abilities

Figure 3 illustrated the results of problem posing by annotated expressions and pure expressions on general problem-solving abilities. The result of the ANOVA indicated that there was a significant interaction between groups and time $(F(1,27)=4.298, p<.05)$. Two paired sample $t$ tests further showed that both groups had significant improvement (the experimental group: $t(14)=6.162$, $p<.05$; the control group: $t(13)=3.331, p<.05)$, confirming the previous finding that problem posing can enhance the problem-solving abilities. Furthermore, although an independent sample $t$ test showed that there was no significant difference in the performance of the post-test between the two groups $(t(27)=1.196, p>.05)$, the significant interaction suggested that the differences in the improvement between both groups existed. The reason perhaps was that annotated expressions were effective for a certain part of problem-solving abilities rather than general abilities. For this reason, the next two sections will look into the effects on the each part of the assessment.

The effects on problem translation and integration abilities

This study further examined the effect of annotated expressions and pure expressions on problem translation and integration abilities. Figure 4a illustrated the average scores of both groups in terms of problem translation abilities. Paired sample $t$ tests showed that the experimental group had significant improvement $(t(14)=3.71, p<.05)$, while the control group did not showed significant improvement $(t(13)=0.69, p>.05)$. The result suggested that problem posing by annotated expressions could enhance students' problem translation abilities instead of problem posing by pure expressions.

Figure $4 \mathrm{~b}$ illustrated the average scores of both groups in terms of problem integration abilities. Paired sample $t$ tests showed that not only the experimental group significantly improved their problem integration abilities $(t(14)=5.010$, $p<.05)$, but also the control group significantly improved $(t(13)=3.42, p<.05)$. This result suggested that problem posing by both annotated expressions and pure expressions may enhance students' problem integration abilities.

These results indicated that problem posing by annotated expression may effectively increase the abilities to transform and integrate the information in word problems, while problem posing by pure expressions may only help the problem integration abilities. The possible reason was that annotated expressions provided clearer structures of word problems. When students created problems by annotated expression, they continuously considered the relationship among word problems, conditions, and structures, facilitating their ability to understand a problem. 
Fig. 3 The result of problemsolving ability assessment

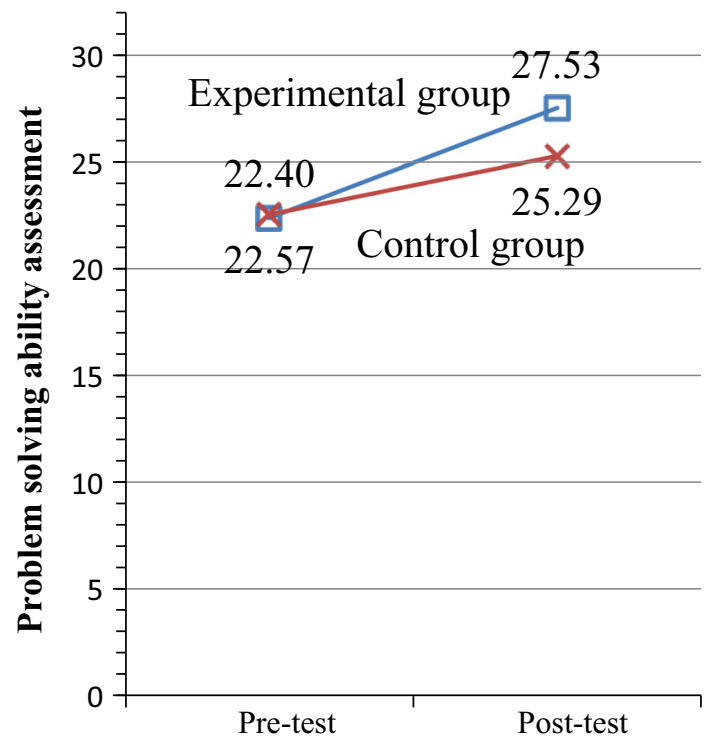

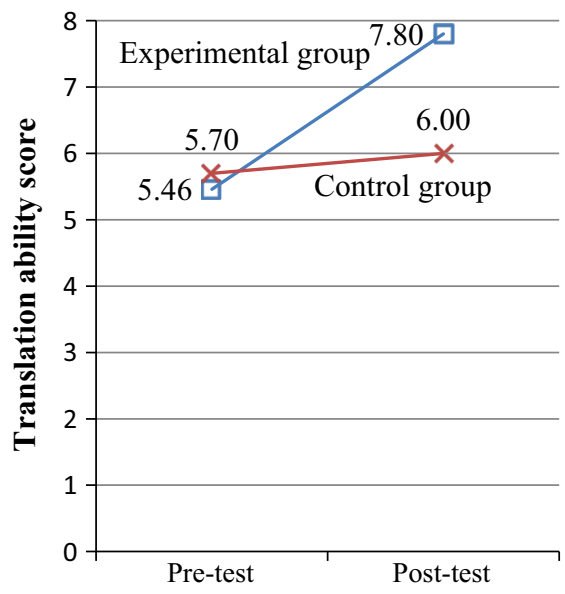

(a)

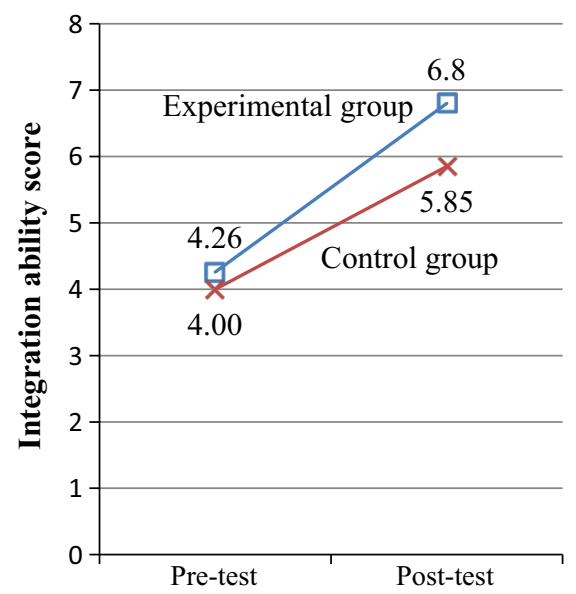

(b)

Fig. 4 The results of problem understanding abilities. a Problem translation ability. b Problem integration ability

However, with pure expressions only, students did not usually think about the problem target or conditions. Rather, they contextualized the arithmetic expressions directly, limiting the improvement in problem translation abilities. 
The effects on formulation abilities in one-step and two-step problems

In order to examine the effects of both materials for problem posing on formulation abilities, this study included one-step and two-step word problems. Figure 5a illustrated the results of one-step word problems. Unfortunately, paired sample $t$ tests did not reveal significant improvement for both experimental group $(t(14)=1.59, p>.05)$ and control group $(t(13)=1.44, p>.05)$. This reason was possibly the ceiling effect. Specifically, because one-step word problems were pretty easy for fourth graders, both groups achieved rather high performance in their pre-test, resulting in limited improvement.

Figure $5 \mathrm{~b}$ illustrated the results of two-step word problems. This study further conducted paired sample $t$ tests. The results indicated that the experimental group significantly improved their formulation abilities in two-step problems $(t(14)=2.65, p<.05)$, while the improvement of the control group was not significant $(t(13)=0.44, p>.05)$. The results suggested that annotated expressions could enhance students' abilities to formulate two-step problems, because the annotation and structures provided sufficient scaffolding. With annotated expressions, students may easily imagine and compose two-step word problems, facilitating their formulation abilities as well.

\section{Computer-supported problem posing by annotated expressions}

The aforementioned experiment proved that problem posing by annotated expressions could enhance students' problem-solving abilities, especially problem understanding abilities and two-step problem formulation abilities. Based on the results, this study designed a computer-based system to support and sustain the learning activity.

\section{Requirements}

During the aforementioned experiment, the authors collected observation notes, which may assist to design a computer version of annotated expressions. This section described four issues that could be supported by computers.

\section{Work sharing}

It was observed that when students completed assigned word problems, they were visibly eager to show their works to their neighboring classmates. Furthermore, besides classmates, some students told the researchers that they would also share their word problems with their teacher and even parents. On the other hand, students had curiosity about the other classmates' works. They tended to consciously or unconsciously compare posed problems of each other, which may help them learn from others' works. However, paper-based materials limited students to sharing works with a small part of people, which could be overcome in a computer version. 


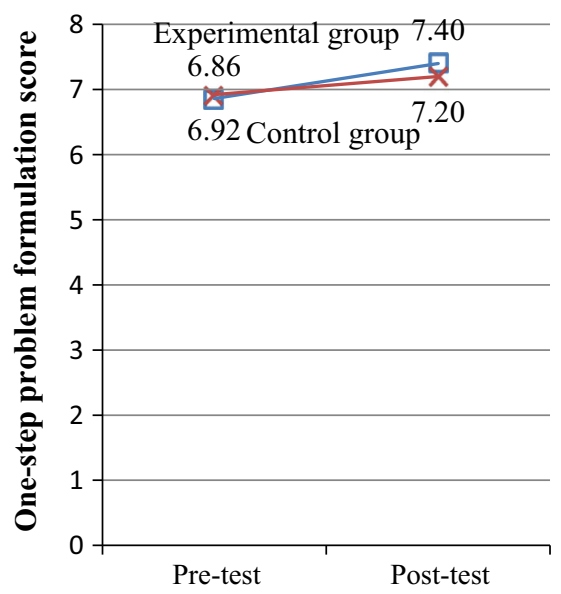

(a)

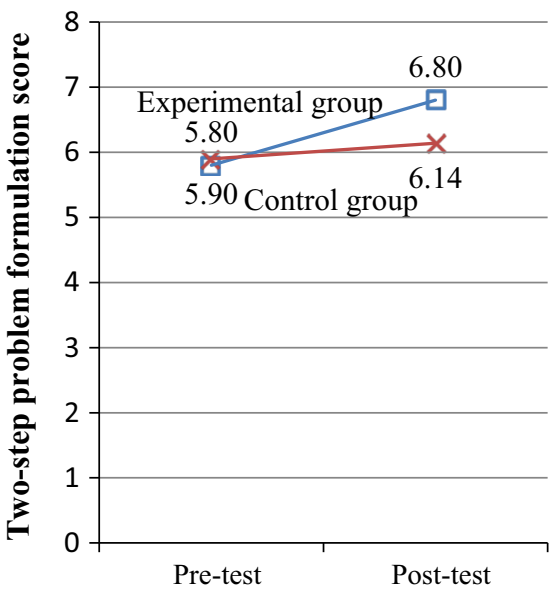

(b)

Fig. 5 The results of formulation abilities. a One-step problems. b Two-step problems

\section{Reciprocal problem solving}

Most students told the researchers that their motivation for problem posing was to quiz their classmates so that they could know whether they pose good word problems. The previous experiment lacked an opportunity for solving each other's problems, because it was inconvenient for teachers to conduct reciprocal problem solving with paper-based materials. As a result, students felt unsatisfied and unmotivated to pose word problems. With the support of computers, the posed problems may be immediately stored and assigned to appropriate students, increasing the incentive to pose word problems.

\section{Teacher monitoring}

The teacher, who played the role of a conductor and observer in the paper-based experiment, told the researchers that problem posing could be an appropriate formative assessment to understand the mathematical abilities of every student. However, due to the limitation of paper-based materials, it was difficult for her to understand students' works immediately. If computers could help teachers monitor the posed problem of the whole class, teachers were able to control the activity more easily and diagnose the misconceptions of students.

\section{Teachers' feedback}

When students devised their word problems in the experiment, they sometimes posed irrelevant or inappropriate statements in their works. It was difficult for teachers to give these students immediate advices with the paper-based materials. On the other hand, for the students who posed creative or elaborate word problems, 
it was necessary to encourage them immediately as well. For this reason, a computer-based version would include the functions of feedback for teachers, so that teachers could provide students with instructional feedback.

\section{System design}

According to the requirements of teachers and students, Fig. 6 illustrated the activity flow of computer-supported problem posing by annotated expressions. By contextualizing an arithmetic expression, students could give meaning and life to mathematics, which they usually felt difficult and cold. When students thought that mathematics was related to their real life and could be used to solve daily problems, they may find that learning mathematics was meaningful and interesting. For this reason, this study chose daily experience as the main scenario. More specifically, this study provided a scenario of store management, so that students may play the role of store manager. The scenario may help students imagine a meaningful word problem.

Every student in a classroom could play a manager of different stores, situated in the same town. These stores, for example, a clothing store, a fruit store, a restaurant, a grocer, and so on, were all shown in the map of the town (Fig. 7a). The students had to name their own stores, so that they may feel the stores belong to them. The sense of belonging may help them engage in the mathematical activity. As store managers, they should adopt the perspective of the role to design word problems.

After setting a role, every student started to pose a word problem with the help of annotated expressions (Fig. 7b). It should be noted that every student was assigned a different annotated arithmetic expression unlike the paper-based experiment because the classmates may answer his/her word problem. Based on the assigned scenarios and annotated arithmetic expressions, students were required to devise their own problems. For their convenience, the system provided several buttons of punctuation and numbers.

When students completed their word problems, the system recorded these problems in the database. At this time, the map of the town also allows students to share their word problems with classmates (Fig. 7c). Their word problems may thus have opportunity to be assessed in this way. Through this stage, students could also learn how to appreciate and criticize the word problems posed by their classmates. During this two stages, their teacher may monitor their progresses and provide them with feedback to instruct or encourage them depending on the qualities of their works.

After all students posed their problems, the teacher may allow them to solve word problems of other students. The system would assign every student to solve three problems. Specifically, students were informed that they had to collect three treasures in three different stores. When they entered an assigned store, the word problem posed by the store manager was displayed (Fig. 7d). They could acquire the treasures as long as they were able to answer the word problem correctly. If they found that the word problem was unsolvable, they could press an "unsolvable" button to change another problem. This information was recorded so that the teacher could give further suggestions to the problem poser. 


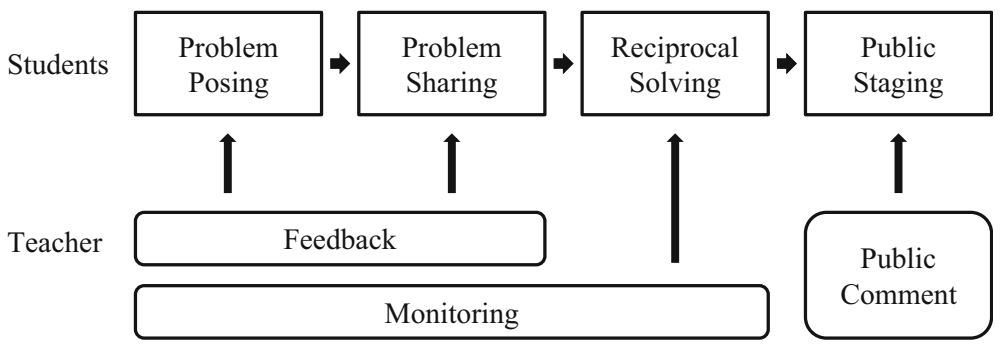

Fig. 6 Computer-based activity flow

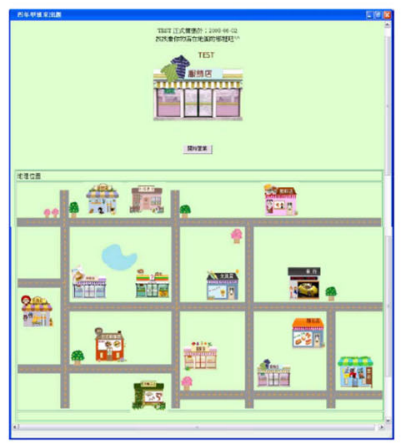

(a)

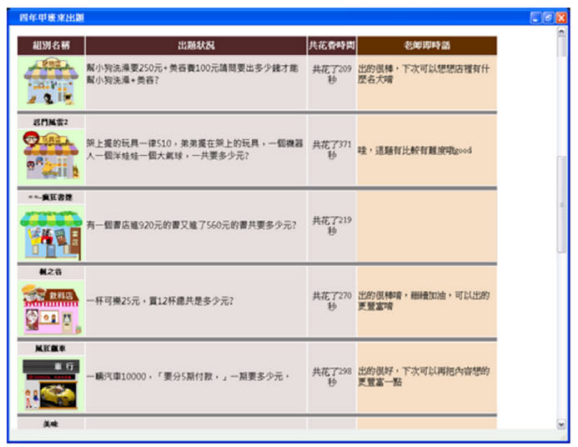

(c)

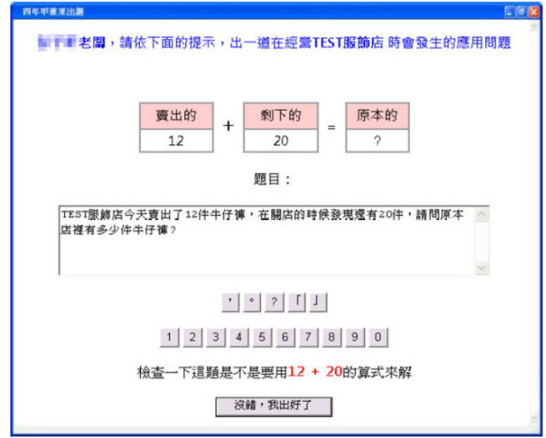

(b)

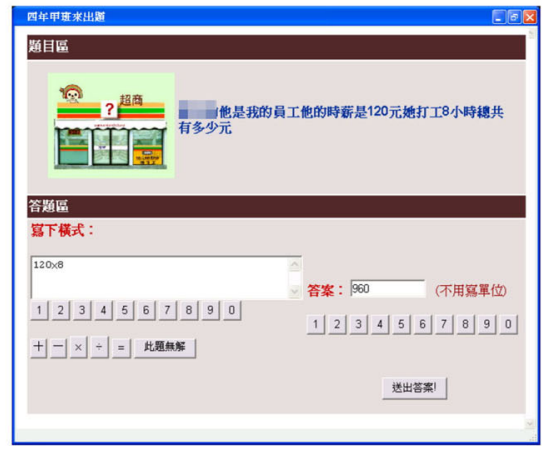

(d)

Fig. 7 Computer-based annotated expressions for problem posing. a The scenario of a town map. b The problem posing area. c The problem sharing area. d The reciprocal solving area

In the last 10 min of every session, the teacher conducted an event of public staging, in which students may raise their hands to volunteer introducing their posed problems in public. When a problem poser finished an introduction, the rest of students may ask him/her a question about their word problem and the poser attempted to answer the question. At last, the teacher made a public comment, so that the students may receive an authoritative feedback. 


\section{Classroom adoption}

Adoption goals

Although the aforementioned experiment confirmed that problem posing by annotated expressions could improve problem-solving abilities, it could not guarantee smooth adoption. The may be due to the fact that the sophisticated design of an experiment was far away from authentic classrooms, in which students might behave differently and naturally. For this reason, this study included the adoption of the system in a classroom, where researchers may observe students' behaviors instead of investigating the effectiveness. Specifically, the goal of the adoption was to preliminarily understand the feasibility of the system as well as students' behaviors through observation.

\section{Settings}

The same 29 fourth grade students in the previous experiment were invited to participate in the activity of adoption. For using the system, every student was provided with a netbook. Because they had a course in information education since their third grade in Taiwan, they had basic capabilities to use computers and type Chinese words. The activity took three sessions of classes within 2 weeks. During the activity, the students were required to pose a word problem in the system with the support of annotated expressions (as shown in Fig. 7), while the teachers needed to coordinate the activity, such as giving mini lessons, monitoring students' works, and providing feedback.

As in the aforementioned experiment, when the teacher conducted the activity, six researchers observed students' behaviors and took notes. In particular, the observation focused on their emotional actions in using the system (e.g., a laugh, a trance or contemplation), their individual utterances in using the system (e.g., a soliloquy or murmuring), and the discourses between students (e.g., a chat or sharing opinions). The three sessions of the activity were also videotaped. Besides, after every session, some students actively talked to the researchers about the system, while some students discussed their usage with each other. These conversations were also recorded in observation notes. Through these notes, the authors may generalize several similarities, which will be described in the next section.

\section{Preliminary observation}

The first observation was that students were all able to pose their problems with computers, while the teachers could handle the progresses of problem posing and solving as well as control the time for conducting the activities using the monitoring interface. Most importantly, there were three major findings observed in this adoption in terms of enjoyment, attitudes, and responsibility. 


\section{Enjoyment}

The system incorporated the scenario of store management, which visibly raised students' enjoyment for problem posing. Furthermore, students cared about which store they owned. After every session, for example, they excitedly talked about their stores and the locations on the map of the town. They were delighted that they could become the owner of the stores, expecting the next activities. Some students suggested the paper-based materials should incorporate store management as well, implying that they accepted and liked such a scenario. Besides, although the scenario seemed a constraint of problem posing, it actually guided students to devise a contextualized word problem and enhanced their senses of ownership.

\section{Activeness}

When sharing posed problems, the students visibly concerned the content of every word problem. They paid attention to the latest word problems in the sharing area at all times. Furthermore, it was observed that the students compared their word problems with the others' in the sharing area. An informal talk with some students revealed that they expected their posed problems were better than the others'. Besides, they also very cared about the teacher's suggestions, which may improve their word problems. Interestingly, students concerned the correctness of their problem solved by other classmates. Specifically, they felt happy when someone answered their problems incorrectly. These findings implied that the sharing area and teacher's feedback of computer-based problem posing potentially resulted in students' activeness.

\section{Responsibility}

The students indicated that they preferred typing than handwriting when posing word problems. In particular, there were only five students who were proficient in typing and careful with using punctuations. When facing difficult Chinese words, they looked them up in the dictionary. Surprisingly, the rest of students, who were not skillful at typing, strongly insisted on typing by themselves. Even though they typed slowly, they did not want others' helps. They anticipated that they could complete the word problem in their own ways. They asked themselves to use correct punctuations and fluent sentences without typing wrong words. The findings suggested that the students had strong responsibility for posing a word problem with a high standard in a computer-based environment.

\section{Discussion and conclusions}

The purpose of learning mathematics is to connect mathematical knowledge and their daily life. In order to construct mathematical word problems, students may invest their knowledge and experience. Previous research has found that students with high problem-solving ability can pose a word problem involving higher 
complexity, while low-ability students show less creative (English 1998; Silver \& Cai 1996). In other words, they tend to change numbers or several words rather than designing their own word problems. Moreover, without certain guidance, most students usually propose what they are familiar with. Therefore, it is necessary to design appropriate problem posing materials to support students to design and challenge various mathematical concepts.

For this reason, this paper contributes to propose a systematic framework of problem solving and posing in terms of intermediate products, including problem situation, natural language, target/conditions, structure/representations, expressions and answers, on the basis of previous literature (Kintsch \& Greeno 1985; Mayer 1985; Pólya 1945). This framework potentially raises a series of research on problem posing with or without computers. In particular, researchers may notice what is missing in the framework to design various learning materials for problem posing in the future, depending on their educational objectives. Alternatively, they may also compare the difference in the effects of intermediate products for problem posing.

The current research on computer-based problem posing mainly focuses on peer assessment by taking advantage of network technology (Barak \& Rafaeli 2004; Lan \& Lin 2011; Yu 2011). In this vein, such research leads to the design of general problem types and considers the supports after the process of problem posing more than in the process, even in some studies on computer-based mathematical problem solving (Chang et al. 2012; Lin 2010).

On the other hand, although innovative technology continuously expands the edge of digital learning, the mature of current information technology shall lead to adoption-based research (Chan et al. 2006). Adoption-based research should consider the setting of authentic classrooms instead of an experiment-oriented environment. For this reason, this study adopts a content-first design approach, proposed by Chang et al. (2009), which involves content samples, an assessment goal, a learning flow, and finally adoption. The approach emphasizes that a curriculum is more essential than technology in adopting digital learning.

First, in terms of the content-first design approach, this study designs annotated expressions as content samples in order to support students to pose word problems with a clear problem structures. Problem posing by annotated expressions is different from changing variables in given examples (Kojima et al. 2009) and organizing problem conditions (Hirashima et al. 2008), which focus more on the levels of words and sentences, respectively. It is also different from freely creating a word problem with scenarios (Birch \& Beal 2008), expressions or only values, which are essentially to write a story. The annotated expressions may allow students to observe the problem structure and to fit the requirement of the values with annotation and operators. Being familiar with different structures may help students create various word problems as well as realize how to solve these word problems.

Second, the study chooses problem-solving abilities as the assessment goal in the content-first design approach. In order to examine the effects of annotated expressions, an experiment was conducted with a control group of pure expressions. Basically, the materials in both groups could improve students' problem-solving abilities, which was consistent with previous research that problem posing may 
facilitate problem solving (Silver 1994; Silver \& Cai 1996; Cai \& Hwang 2002; English 2003). However, the results further showed that problem posing by annotated expressions, compared with pure expressions, may enhance students' problem-solving abilities in terms of problem translation abilities and two-step problem formulation abilities.

Third, based on the results and observation notes of the experiment, this study designed a learning flow and a corresponding system. The learning flow included four stages, that is, problem posing, problem sharing, reciprocal solving, and public staging. In a sense, computers assist teachers to manage the activity of problem posing and provide students with more opportunities to share works and reflect themselves. Compared with Leung's framework (1993) and its related systems (e.g., Chang et al. 2012), this study encourages students to solve each other's problems instead of their own problems. However, the current version of the learning flow lacks the function of peer assessment in order to increase the qualities of students' works (e.g., Yu 2011), which should and will be incorporated in the future.

Finally, a preliminary classroom adoption showed that students were able to pose mathematical word problems with computers, while the teacher could easily control the computer-based activity. Most importantly, students visibly showed their enjoyment, activeness, and responsibility in mathematical problem posing. In particular, besides annotated expressions, the system adopted a scenario of store management. With the support of interesting scenarios, students may not only imagine reasonable word problems that happen in their real life, but also develop their diverse thinking (English 1998). In the end, students may learn not only problem solving, but also creating their own mathematical knowledge.

Acknowledgments The authors would like to thank Ministry of Science and Technology of the Republic of China, Taiwan, for financial support (103-2511-S-008-009-MY3, 101-2511-S-008-016-MY3, 103-2811-S-008-001), and Research Center for Science and Technology for Learning, National Central University, Taiwan. The authors would also like to thank Winston M.C. Wu, Yi-ju Lin, Tzu-Chao Chien, Chih-Ting Chang, and Po-Shu Chen for their assistance during the data collection processes.

\section{References}

Aebli, H., Ruthemann, U., \& Staub, F. C. (1986). Sind regeln des problemlösens lehrbar? Zeitschrift für Pädagogik, 32, 617-638.

Anderson, L. W., \& Krathwohl, D. R. (2001). A taxonomy for learning, teaching, and assessing: A revision of bloom's taxonomy of educational objectives. New York, NY: Longman.

Arikan, E. E., \& Unal, H. (2014). Development of the structured problem posing skills and using metaphoric perceptions. European Journal of Science and Mathematics Education, 2(3), 155-166.

Barak, M., \& Rafaeli, S. (2004). On-line question-posing and peer-assessment as means for web-based knowledge sharing in learning. International Journal of Human-Computer Studies, 61(1), 84-103.

Basic Education Curriculum Material Development Center, National Ministry of Education. (2001). national mathematics curriculum standards at the compulsory education level [in Chinese]. Beijing, China: Beijing Normal University.

Birch, M., \& Beal, C. R. (2008). Problem posing in AnimalWatch: An interactive system for studentauthored content. In D. Wilson \& H. C. Lane (Eds.), Proceedings of the Twenty-First International Florida Artificial Intelligence Research Society Conference (pp. 397-402). Miami, FL: AAAI Press.

Brown, S. I., \& Walter, M. I. (1993). Problem posing in mathematics education. In S. I. Brown \& M. I. Walter (Eds.), Problem posing: Reflection and applications (pp. 16-27). Hillsdale, NJ: Lawrence Erlbaum Associates. 
Brown, S. I., \& Walter, M. I. (2005). The art of problem posing. Mahwah, NJ: Lawrence Erlbaum Association.

Cai, J., \& Hwang, S. (2002). Generalized and generative thinking in U.S. and Chinese students' mathematical problem solving and problem posing. Journal of Mathematical Behavior, 21(4), 401-421.

Cai, J., \& Nie, B. (2007). Problem solving in Chinese mathematics education: research and practice. ZDM: The International Journal on Mathematics Education, 39(5), 459-473.

Chan, T. W., Roschelle, J., His, S., Kinshuk, Sharples, M., Brown, T., et al. (2006). One-to-one technology enhanced learning: An opportunity for global research collaboration. Research and Practice in Technology Enhanced Learning, 1(1), 3-29.

Chang, S. B., Lin, C. J., Ching, E., Cheng, H. N. H., Chang, B., Chen, F. C., et al. (2009). EduBingo: Developing a content sample for the one-to-one classroom by the content-first design approach. Educational Technology \& Society, 12(3), 343-353.

Chang, K. E., Sung, Y. T., \& Lin, S. F. (2006). Computer-assisted learning for mathematical problem solving. Computers \& Education, 46(2), 140-151.

Chang, K. E., Wu, L. J., Weng, S. E., \& Sung, Y. T. (2012). Embedding game-based problem-solving phase into problem-posing system for mathematics learning. Computers \& Education, 58(2), $775-786$.

Derry, J. S., \& Hawkes, L. W. (1993). Local cognitive modeling of problem solving behavior: An application of fuzzy theory. In S. P. Lajoie \& S. J. Derry (Eds.), Computers as cognitive tools (pp. 107-140). Hillsdale, NJ: Lawrence Erlbaum Associates.

Dillon, J. T. (1982). Problem finding and solving. Journal of Creative Behavior, 16(2), 97-111.

Duncker, K. (1945). On problem solving. Psychological monographs, 58(5), 1-113.

English, L. D. (1996). Children's problem posing and problem solving preferences. In J. Mulligan \& M. Mitchelmore (Eds.), Research in early number learning (pp. 227-242). Adelaide, Australian: Australian Association of Mathematics Teachers.

English, L. D. (1998). Children's problem posing within formal and informal context. Journal for Research in Mathematics Education, 29(1), 83-106.

English, L. D. (2003). Problem posing in the elementary curriculum. In F. Lester \& R. Charles (Eds.), Teaching mathematics through problem solving (pp. 187-198). Reston, VA: National Council of Teachers of Mathematics.

Freire, P. (2001). Pedagogy of the Oppressed. London, UK: Bloomsbury Academic.

Hirashima, T., Yokoyama, T., Okamoto, M., \& Takeuchi, A. (2006). A computer-based environment for learning by problem-posing as sentence-integration. In R. Mizoguchi, P. Dillenbourg, \& Z. Zhu (Eds.), Proceeding of the 14th International Conference on Computers in Education (pp. 127-130). Beijing, China: Asia-Pacific Society for Computers in Education.

Hirashima, T., Yokoyama, T., Okamoto, M., \& Takeuchi, A. (2008). An experimental use of learning environment for problem-posing as sentence-integration in arithmetical word problems. In B. P. Woolf, E. Aïmeur, R. Nkambou, \& S. P. Lajoie (Eds.), Proceedings of the 9th International Conference on Intelligent Tutoring Systems (pp. 687-689). Montreal, Canada: Springer.

Kar, T., Özdemir, E., İpek, A. S., \& Albayrak, M. (2010). The relation between the problem posing and problem solving skills of prospective elementary mathematics teachers. Procedia: Social and Behavioral Sciences, 2(2), 1577-1583.

Kintsch, W., \& Greeno, J. G. (1985). Understanding and solving word arithmetic problems. Psychological Review, 92(1), 109-129.

Koichu, B., \& Kontorovich, I. (2013). Dissecting success stories on mathematical problem posing: a case of the billiard task. Educational Studies in Mathematics, 83(1), 71-86.

Kojima, K., \& Miwa, K. (2008). A system that facilitates diverse thinking in problem posing. International Journal of Artificial Intelligence in Education, 18(3), 209-236.

Kojima, K., Miwa, K., \& Matsui, T. (2009). Study on support of learning from examples in problem posing as a production task. In S. C. Kong et al. (Eds.), Proceedings of the 17th International Conference on Computers in Education (pp. 75-82). Hong Kong: Asia-Pacific Society for Computers in Education.

Lan, Y. F., \& Lin, P. C. (2011). Evaluation and improvement of student's question-posing ability in a web-based learning environment. Australasian Journal of Educational Technology, 27(4), 581-599.

Lavy, I., \& Shriki, A. (2007). Problem posing as a means for developing mathematical knowledge of prospective teachers. In J.-H. Woo, H.-C. Lew, K.-S. Park, \& D.-Y. Seo (Eds.), Proceedings of the 
31st Conference of the International Group for the Psychology of Mathematics Education (Vol. 3, pp. 129-136). Seoul, Korea: The Korea Society of Educational Studies in Mathematics.

Leung, S. S. (1993). Mathematical problem posing: The influence of task formats, mathematics knowledge, and creative thinking. In I. Hirabayashi, N. Nohda, K. Shigematsu, \& F. Lin (Eds.), Proceedings of the 17th Conference of the International Group for the Psychology of Mathematics Education (Vol. 3, pp. 33-40). Tsukuba, Japan: International Group for the Psychology in Mathematics Education.

Lin, G. Y. (2010). Evaluating satisfaction regarding interaction with a collaborative problem posing and solving learning system. In V. Mahadevan \& G. S. Tomar (Eds.), Proceedings of the 2nd International Conference on Educational Technology and Computer (Vol. 4, pp. 481-484). Shanghai, China: Institute of Electrical and Electronics Engineers Inc.

Mayer, R. E. (1985). Mathematical Ability. In R. J. Sternberg (Ed.), Human abilities: An information processing approach (pp. 127-150). New York, NY: Freeman.

Mayer, R. E. (1992). Thinking, problem solving, cognition. New York, NY: Freeman.

Ministry of Education of Taiwan. (2000). Nine-year integrated curriculum guidelines for mathematics [in Chinese]. Taipei, Taiwan: Ministry of Education of Taiwan.

National Council of Teachers of Mathematics (NCTM). (1989). Curriculum and evaluation standards for school mathematics. Reston, VA: National Council of Teachers of Mathematics Inc.

National Council of Teachers of Mathematics (NCTM). (1991). Professional standards for teaching mathematics. Reston, VA: National Council of Teachers of Mathematics Inc.

National Council of Teachers of Mathematics (NCTM). (1995). Assessment standarts for school mathematics. Reston, VA: National Council of Teachers of Mathematics Inc.

National Council of Teachers of Mathematics (NCTM). (2000). Principles and standards for school mathematics. Reston, VA: National Council of Teachers of Mathematics Inc.

Pelczer, I., \& Rodriguez, F. G. (2010). Creativity assessment in school settings through problem posing tasks. The Montana Mathematics Enthusiast, 8(1-2), 383-398.

Pólya, G. (1945). How to solve it: A New aspect of mathematical method. Princeton, NJ: Princeton University Press.

Reusser, K. (1996). From cognitive modeling to the design of pedagogical tools. In S. Vosnadiou, E. De Corte, R. Glaser, \& H. Mandl (Eds.), International perspectives on the design of technology supported learning environments (pp. 81-104). Hillsdale, NJ: Lawrence Erlbaum Associates.

Silver, E. A. (1994). On mathematical problem posing. For the Learning of Mathematics, 14(1), 19-28.

Silver, E. A. (1997). Fostering creativity through instruction rich in mathematical problem solving and problem posing. ZDM: The International Journal on Mathematics Education, 97(3), 75-80.

Silver, E. A., \& Cai, J. (1996). An analysis of arithmetic problem solving by middle school students. Journal for Research in Mathemetics Education, 27, 521-539.

Stoyanova, E., \& Ellerton, N. F. (1996). A framework for research into students' problem posing in school mathematics. In P. Clarkson (Ed.), Technology in mathematics education (pp. 518-525). Melbourne, Australia: Mathematics Education Research Group of Australasia.

Yamamoto, S., Hashimoto, T., Kanbe, T., Yoshida, Y., Maeda, K., \& Hirashima, T. (2013). Interactive environment for learning by problem-posing of arithmetic word problems solved by one-step multiplication. In L.-H. Wong, C.-C. Liu, T. Hirashima, P. Sumedi, \& M. Lukman (Eds.), Proceedings of the 21st International Conference on Computers in Education (pp. 51-60). Bali, Indonesia: Asia-Pacific Society for Computers in Education.

Yamamoto, S., Kanbe, T., Yoshida, Y., Maeda, K., \& Hirashima, T. (2012). A case study of learning by problem-posing in introductory phase of arithmetic word problems. In G. Biswas, L.-H. Wong, T. Hirashima, \& W. Chen (Eds.), Proceedings of the 20th International Conference on Computers in Education (pp. 25-32). Singapore: Asia-Pacific Society for Computers in Education.

Yu, F. Y. (2011). Multiple peer-assessment modes to augment online student question-generation processes. Computers \& Education, 56(2), 484-494.

Yuan, X., \& Sriraman, B. (2011). An exploratory study of relationships between students' creativity and mathematical problem-posing abilities: Comparing Chinese and U. S students. In B. Sriraman \& K. Lee (Eds.), The elements of creativity and giftedness in mathematics (pp. 5-28). Rotterdam: Sense Publishers.

Zhang, D. (2006). Theoretical and empirical studies on mathematics teaching for "two basics" in China [in Chinese]. Shanghai, China: Shanghai Educational Press. 
Hercy N. H. Cheng received his Ph.D. degree in the Department of Computer Science and Information Engineering at National Central University in Taiwan. Dr. Cheng is currently an associate professor and researcher in Collaborative and Innovative Center for Educational Technology at Central China Normal University in China.

Yu-Lin Weng received her M.S. degree in the Graduate Institute of Network Learning Technology at National Central University in Taiwan. She is currently a lecturer of the Department of Information Management as well as a section chief of registrar at the office of academic affair at St. Mary's Junior College of Medicine, Nursing and Management in Taiwan.

Tak-Wai Chan is a Chair Professor of the Graduate Institute of Network Learning Technology at National Central University in Taiwan. He has researched on various areas of digital technology supported learning, including artificial intelligence in education, computer supported collaborative learning, digital classrooms, online learning communities, mobile and ubiquitous learning, digital game based learning, and, most recently, technology supported mathematics and language arts learning. 